\title{
B7-H4 promotes tumor growth and metastatic progression in lung cancer by impacting cell proliferation and survival
}

\author{
Xiuqin Zhang ${ }^{1,3}$, Liming $\mathrm{Cai}^{3}$, Guangbo Zhang ${ }^{2}$, Yu Shen ${ }^{2}$, Jianan Huang ${ }^{1,2}$ \\ ${ }^{1}$ Department of Respiratory Medicine, The First Affiliated Hospital of Soochow University, Suzhou 215006, China \\ ${ }^{2}$ Clinical Immunology Laboratory of Jiangsu Province, Suzhou 215006, China \\ ${ }^{3}$ Department of Respiratory Medicine, The Affiliated Hospital of Jiangnan University (WuXi No.4 People's Hospital), Wuxi \\ 214000, China
}

Correspondence to: Jianan Huang, email: huang_jian_an@163.com

Keywords: B7-H4, lung cancer, tumorigenesis, metastasis

Received: July 22, $2016 \quad$ Accepted: December 16, $2016 \quad$ Published: January 03, 2017

\section{ABSTRACT}

Aberrant expression of B7-H4 occurs across a broad spectrum of human cancers. The aim of this study was to investigate the key role of B7-H4 during tumorigenesis and metastasis of human lung cancer. Our data showed that the shRNA-mediated disruption of B7-H4 markedly inhibited tumor cell proliferation, invasion and migration, increased cell apoptosis and arrested cell cycle at G0/G1. These changes were accompanied by a marked increase in Bax and caspase-3/caspase-8, but a decrease in Bcl-2, cyclinD1 and activation of AKT. In addition, our shRNA-mediated disruption of B7-H4 led to a marked decrease in tumor growth in the immune-compromised mice. Importantly, B7-H4 was expressed in $53.33 \%$ of lung carcinomas from our patient cohort $(n=90)$, but not in any of adjacent non-cancerous tissues, according to our IHC analyses. In particular, B7-H4 expression appeared to be associated with lymph node metastasis $(P=0.008)$ and TNM stage $(P=0.012)$. Taken together, our study demonstrates a strong promoting role of B7-H4 in lung tumor growth, progression and metastasis, and supports its potential as a therapeutic target for the treatment of the disease.

\section{INTRODUCTION}

Lung cancer is one of the leading causes of cancerrelated death in men and the second cause (after breast cancer) in women worldwide [1]. Alarmingly, more than $40 \%$ of patients being initially diagnosed with lung cancer have acquired the advanced-stage disease [2]. While many standard therapies of lung cancer are available, including surgery, chemotherapy, radiotherapy as well as targeted and combined therapies, the overall survival of lung cancer patients remains poor [3]. Therefore, there is an urgent need for development of better predictive biomarkers and target-based therapies for improving the diagnosis and treatment of this aggressive disease.

B7-H4, which is also known as VTCN1, B7x or $\mathrm{B} 7 \mathrm{~S} 1$, is an important member of the B7 family. It has been shown to control cytokine secretion, cytotoxicity development and activation of T cells [4-6]. B7-H4 is also implicated as a promising biomarker and a candidate therapeutic target for multiple types of human cancers [7-13]. Notably, the study by Safaei et_al. demonstrates that B7-H4 is a strong prognostic value and an independent predictor marker for human renal cell carcinoma [7]. There is also evidence that $\mathrm{B} 7-\mathrm{H} 4$ expression correlates with patients' survival and tumor immune response in human melanoma [9]. A similar observation is reported for the patients with esophageal squamous carcinomas [11]. Together, these studies suggest that B7-H4 is a crucial driver of development and progression of human carcinomas. In contrast, there is little known about its role in lung cancer, even though being strongly implicated in the regulation of tumor immunity.

Here, we applied shRNA-mediated gene silencing technology to investigate the functional and signaling roles of B7-H4 in lung tumor growth and progression, as well as underlying molecular mechanisms. Results from our vitro and vivo analyses demonstrate that $\mathrm{B} 7-\mathrm{H} 4$ is a key driver and a promising therapeutic target for human lung cancer. 


\section{RESULTS}

\section{Altered expression of $\mathrm{B} 7-\mathrm{H} 4$ in human tumor and non-tumor specimens}

To evaluate the clinical importance of B7-H4 in lung cancer, we conducted IHC analyses of paraffin-embedded tumors and adjacent non-tumor tissues of lung cancer patients. As shown in Figure 1, B7-H4 protein expression was detected in 48/90 (53.33\%) lung carcinomas and 0/50 $(0 \%)$ non-tumor tissues. In addition, B7-H4 expression was found in the cytoplasm and membrane of cancer cells. These data indicate that the $\mathrm{B} 7-\mathrm{H} 4$ expression is significantly upregulated in lung tumors in our current patient cohort, compared to their adjacent non-cancerous tissues.

\section{Association between B7-H4 expression and clinicopathological characteristics}

Next, we assessed the link between B7-H4 expression and key clinicopathological parameters for our lung cancer patient cohort. As shown in Table 1, B7-H4 expression was associated with lymph node metastasis and pathologic stage (respectively $p=0.008, p=0.012$ ). However, there was lack of association between B7-H4 expression and patients' age, gender, smoking status, pathological type, differentiation and three year survival rate after surgery. Thus, our data imply a strong role of B7-H4 in lung cancer progress and lymph node-associated metastasis.

\section{Lentivirus-mediated expression of B7-H4- specific shRNA in A549 cells}

Human lung cancer cell line A549, which expresses high level of endogenous B7-H4, was applied for our subsequent functional analyses. Here, four different B7-H4 shRNAs were designed to silencing the expression level of B7-H4 gene in A549 cells. With non-specific control shRNA (negative control, NC), B7-H4 mRNA expression level was evaluated by real-time PCR. As shown in Figure 2A, B7-H4-shRNA in A549-B group provided the highest silencing efficiency significantly compared with A549-NC and its knockdown efficiency is up to $71.9 \%$ $(p<0.05)$. Meanwhile, the $\mathrm{B} 7-\mathrm{H} 4$ protein expression level in A549-B was lower than A549-NC group (Figure 2). Therefore, the A549-shRNA-B stable line, named as A549-shRNA cells, was used for our subsequent analyses.

\section{A role of $\mathrm{B} 7-\mathrm{H} 4$ in tumor cell proliferation}

The potential effect of RNAi-mediated B7-H4 down-regulation on A549 cell growth was evaluated by CCK-8 assay. In Figure 3, the results showed that A549shRNA cell growth rate was significantly reduced on day 4 , as compared with A549-NC cells $(p<0.001)$.
A link of B7-H4 to tumor cell migration and invasion

To address the role of B7-H4-shRNA in the aggressive behaviors of A549 cells, we evaluated the influence of B7-H4-shRNA on migration and invasion with transwell assays. As shown in Figure 4, abilities of migration and invasion were significantly inhibited in A549-shRNA cells obviously, compared to that in A549$\mathrm{NC}$ cells $(p<0.001)$. These data demonstrate a promoting role of B7-H4 in the motility and promoted invasion of A549 cells.

\section{A role of $\mathrm{B} 7-\mathrm{H} 4$ in cell cycle progression and apoptosis}

Moreover, the influence of $\mathrm{B} 7-\mathrm{H} 4$ gene silencing on tumor cell cycle was assayed. In Figure 5A, the flow cytometry analysis showed that A549-shRNA cells were arrested in the G0/G1 stage of cell cycle compared to A549-NC cells $(77.70 \pm 6.26 \%$ and $55.25 \pm 8.61 \%$, $p<0.05$ ); while the percentage of $\mathrm{S}+\mathrm{G} 2 / \mathrm{M}$ phase in A549shRNA cells were decreased relative to A549-NC cells $(24.96 \pm 6.10 \%$ and $36.66 \pm 2.96 \%, p<0.05)$. The results showed that the percentage of G0/G1 was increased and the proportion of $\mathrm{S}+\mathrm{G} 2 / \mathrm{M}$ phase was decreased upon B7$\mathrm{H} 4$ ablation. The data indicated that inhibition of B7-H4 resulted in G0/G1 arrest. The G0/G1 arrest in cell cycle could inhibit cell growth and proliferation of cancer. At same time, we detected cell apoptosis in above cells by using Annexin V-PE and 7-ADD double staining. In Figure 5B, the results showed that the percentage of early apoptosis cells in A549-shRNA was higher than the A549-NC $(34.53 \pm 1.44 \%$ and $6.87 \pm 0.15 \% p<0.05)$; there was no difference in percentage of late apoptosis between the two groups $(1.37 \pm 1.10 \%$ and $0.43 \pm 0.06 \%$, $p>0.05$ ). It indicated that inhibition of $\mathrm{B} 7-\mathrm{H} 4$ expression could promote apoptosis of tumor. These results suggested that $\mathrm{B} 7-\mathrm{H} 4$ contributed to tumor progression by apoptosis inhibition.

To investigate which apoptosis and cell cycle pathway components were involved in A549 cells response to B7H4 RNAi, we detected the expression of apoptosis and cell cycle associated molecules by real time PCR and Western blot. We observed the increase of the pro-apoptotic Bax, decrease of anti-apoptotic Bcl-2 and cell cycle associated cyclinD1, and activation of caspase- 3 and caspase- 8 relative to controls. Furthermore, knockdown of B7-H4 decreased AKT phosphorylation, but not changed total AKT protein expression level in A549-shRNA cells (Figure 6).

\section{Effect of B7-H4 knockdown on tumor growth in vivo}

To confirm the function of B7-H4 in lung cancer in vivo, the xenograft tumor model of $\mathrm{BALB} / \mathrm{c}$ nude mice 
Table 1: Correlation of B7-H4 expression with clinicopathologic parameters of NSCLC

\begin{tabular}{|c|c|c|c|c|}
\hline \multirow[t]{2}{*}{ Clinical characteristics } & \multirow[t]{2}{*}{ Case number } & \multicolumn{2}{|c|}{ B7-H4 expression } & \multirow[t]{2}{*}{$P$ value } \\
\hline & & Positive & Negative & \\
\hline All cases & 90 & 48 & 42 & \\
\hline \multicolumn{5}{|l|}{ Age (years) } \\
\hline$<60$ & 42 & 20 & 22 & 0.309 \\
\hline$\geq 60$ & 48 & 28 & 20 & \\
\hline \multicolumn{5}{|l|}{ Gender } \\
\hline Male & 59 & 35 & 24 & 0.116 \\
\hline Female & 31 & 13 & 18 & \\
\hline \multicolumn{5}{|l|}{ Smoking status } \\
\hline Smoker & 55 & 30 & 25 & 0.773 \\
\hline Non-smoker & 35 & 18 & 17 & \\
\hline \multicolumn{5}{|l|}{ Pathological type } \\
\hline Adenocarcinoma & 60 & 29 & 31 & 0.179 \\
\hline Squamous cell carcinoma & 30 & 19 & 11 & \\
\hline \multicolumn{5}{|l|}{ Differentiation } \\
\hline Well & 25 & 15 & 10 & 0.432 \\
\hline Not well & 65 & 33 & 32 & \\
\hline \multicolumn{5}{|l|}{ Pathologic lymph node } \\
\hline No & 34 & 12 & 22 & $0.008^{* *}$ \\
\hline $\mathrm{N} 1+\mathrm{N} 2+\mathrm{N} 3$ & 56 & 36 & 20 & \\
\hline \multicolumn{5}{|l|}{ Pathologic stage } \\
\hline I & 25 & 8 & 17 & $0.012^{*}$ \\
\hline $\mathrm{II}+\mathrm{III}$ & 65 & 40 & 25 & \\
\hline \multicolumn{5}{|l|}{ Survival years after surgery } \\
\hline$<3$ year & 66 & 38 & 28 & 0.181 \\
\hline$\geq 3$ year & 24 & 10 & 14 & \\
\hline
\end{tabular}

Note: $P$ values were calculated using chi-square test; ${ }^{*} p<0.05,{ }^{* *} p<0.01$.

was established by injecting stable A549-shRNA cells and A549-NC cells into the groin of nude. The sizes of tumor volume were shown in Figure 7. The results demonstrated that the tumor volume sizes of nude mice injected with A549-shRNA cells were smaller than nude mice injected with A549-NC cells $(p<0.001)$. Our data indicated that $\mathrm{B} 7-\mathrm{H} 4$ gene silencing results in inhibition of tumor growth.

\section{DISCUSSION}

To date, B7-H4 gene has been intensively studied in many tumors $[8,14-18]$. Here, our study provides key evidence on the role of $\mathrm{B} 7-\mathrm{H} 4$ in tumorigenesis and metastasis of human lung cancer. In particular, the B7$\mathrm{H} 4$ expression is significantly elevated in human lung tumor tissues, while being absent in normal tissues. More importantly, the relationship between B7-H4 expression and clinicopathological factors shows, $\mathrm{B} 7-\mathrm{H} 4$ expression is strongly correlated with lymph node metastasis and pathologic stage.

Our in vitro and vivo studies have demonstrated a strong role of B7-H4 in tumor growth and metastatic progression of lung cancer by use of the RNA interference approach. Notably, our data showed that B7-H4 gene silencing markedly inhibited cell proliferation, invasion and migration, increased cell apoptosis and arrested cell cycle at G0/G1. Apoptosis is critical step for tumor development. The induction of apoptosis is a significant therapeutic strategy for tumor [19]. Bcl-2 blocks apoptosis by preventing pro-apoptotic molecules from mitochondria into the cytosol, while Bax promotes apoptosis by inducing mitochondrial outer membrane permeabilization [20-23]. Increased levels of pro-apoptotic proteins and/or decreased anti-apoptotic proteins can lead to apoptosis. In this study, A549 cell transfection with B7-H4-shRNA led to decrease of anti-apoptotic protein Bcl-2 and increase of the pro-apoptotic protein Bax. As we known, it is the 
$\mathrm{Bax} / \mathrm{Bcl}-2$ ratio that controls the ultimate sensitivity to cell death stimuli [24]. This alteration was responsible for the caspase- 8 and caspase- 3 activation and the induction of apoptosis. Cell cycle progression is also a key step for tumor growth. Targeting cell cycle is also an obvious therapeutic strategy for human cancer [25]. It is well established that the abnormal cell cycle happens in almost all cancers, which is an unavoidable procedure in carcinoma progression. In this article, B7-H4 gene
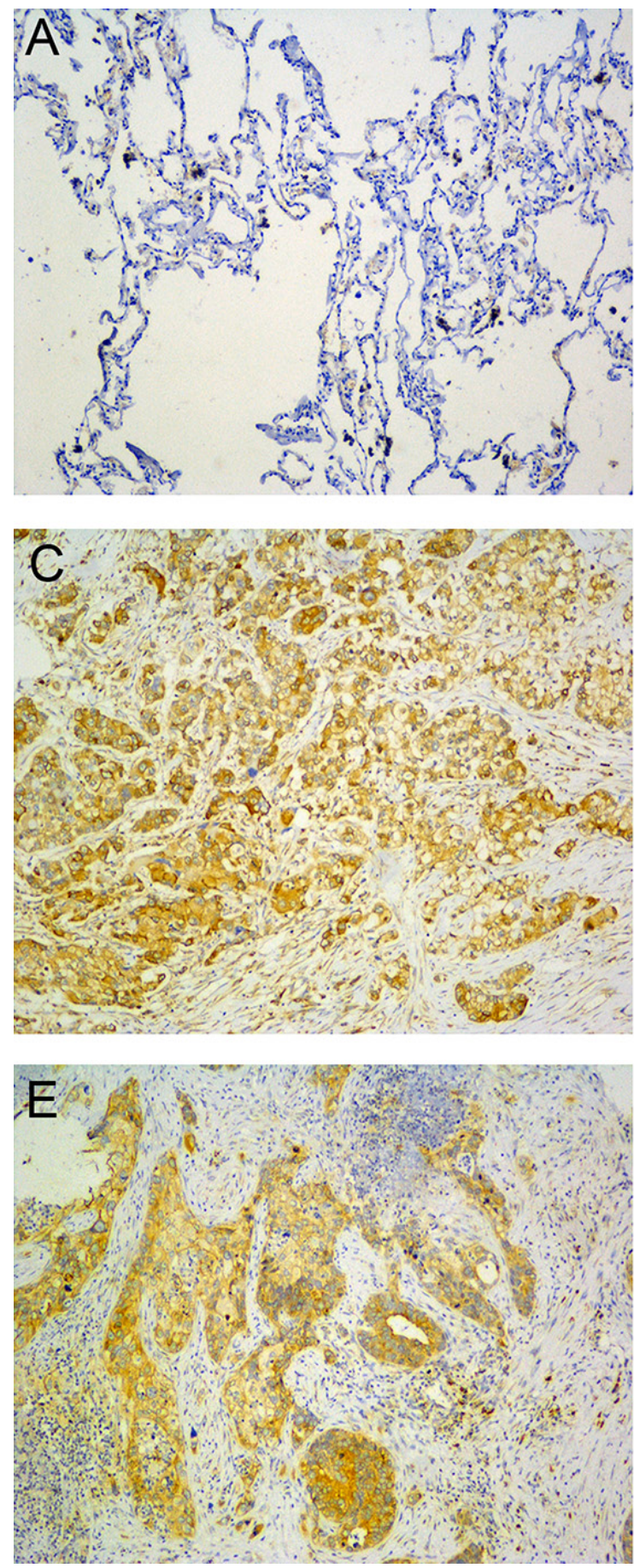

silencing blocked the transformation from G0/G1 phase to $\mathrm{S}$ and $\mathrm{G} 2 / \mathrm{M}$ phase, and followed decrease of cyclin D1 expression. There are complex links between cell cycle and cell apoptosis in tumor. Generally, the apoptosis of cells follows with cell cycle arrest [26]. B7-H4 might be closely bounded with the apoptosis of A549 cells through inhibition of cell cycle.

It is worth noting that the orthotopic xenograft tumor model of nude mice was also established to confirm
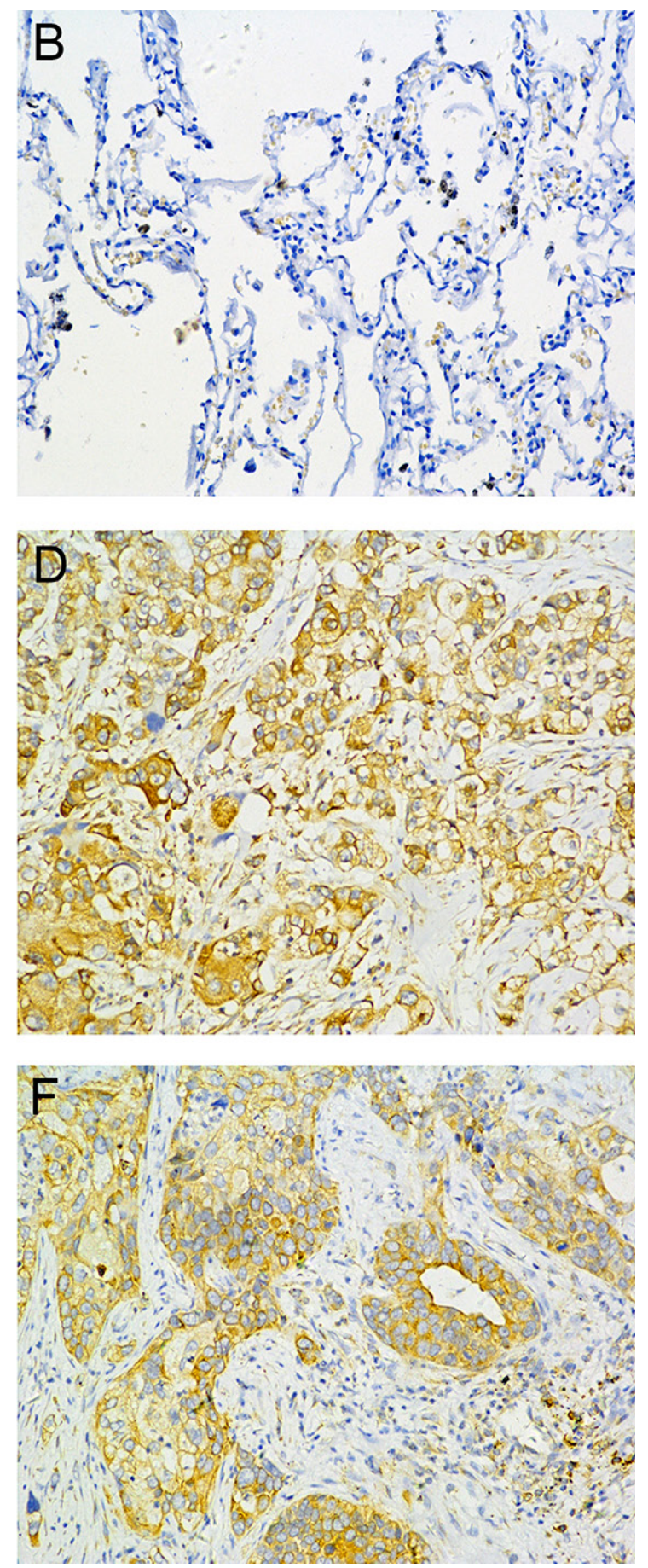

Figure 1: B7-H4 expression in NSCLC. (A, B) normal lung tissue; (C, D) Adenocarcinoma; (E, F) Squamous cell carcinoma. (left: $\mathrm{SP} \times 100$, right: $\mathrm{SP} \times 200)$. 


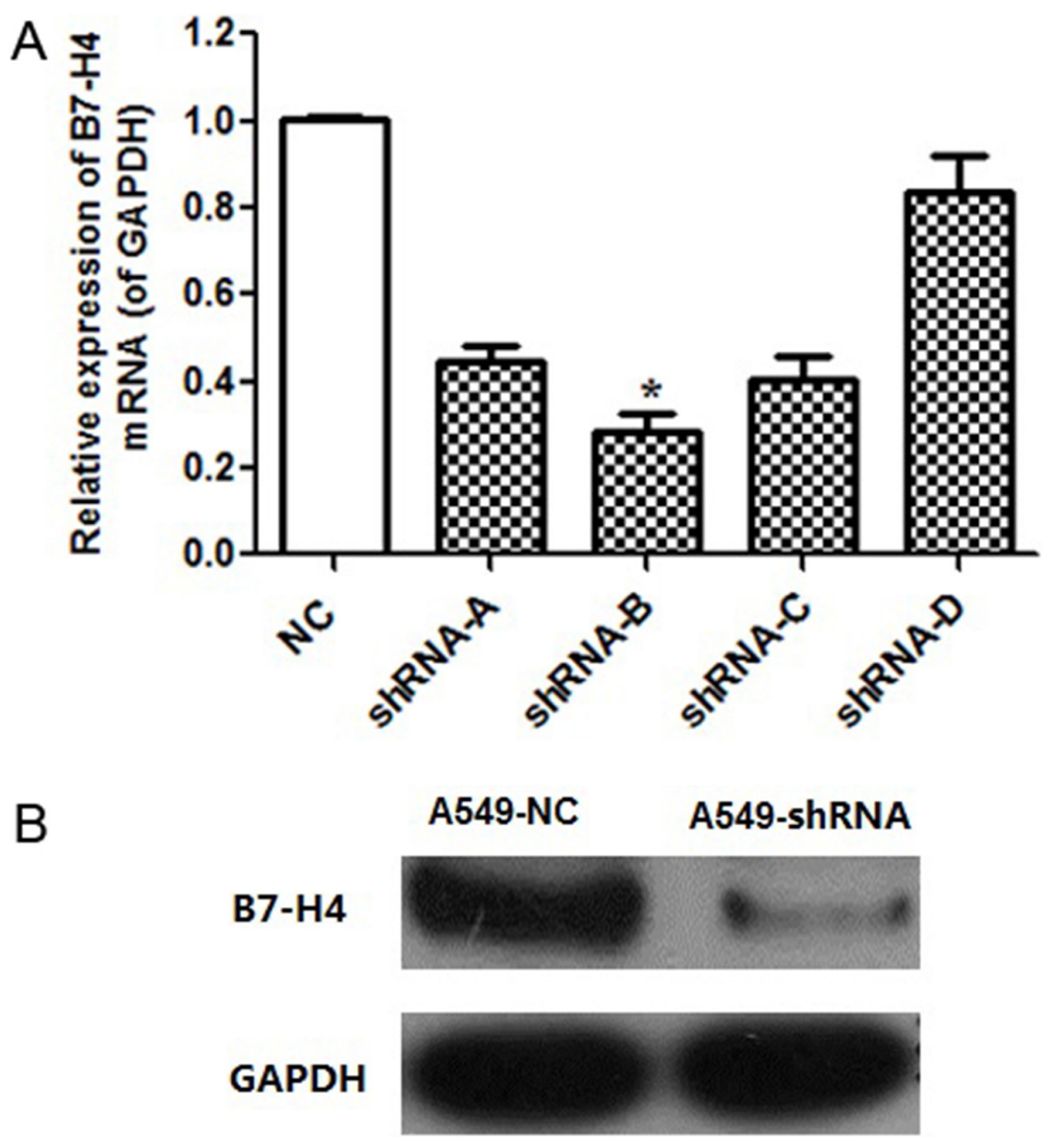

Figure 2: B7-H4 knockdown effect in mRNA and protein level. (A) B7-H4 mRNA level was determined by quantitative RT-PCR. The level of B7-H4 mRNA expression in A549-shRNA-B cells was decreased by approximately 71.9\% compared with A549-shRNA-A, A549-shRNA-C or A549-shRNA-D. (B) The level of B7-H4 protein expression in A549-shRNA-B cells was decreased significantly compared with A549-NC cells by western blot. Data was presented as the mean $\pm \mathrm{SD} ;{ }^{*} p<0.05$.

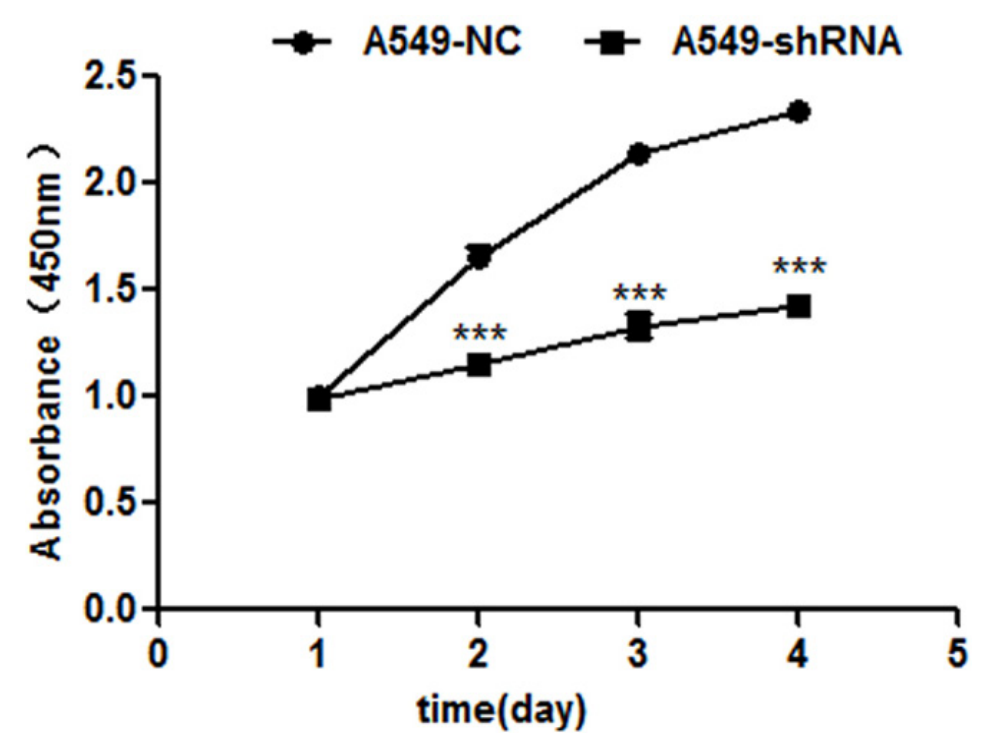

Figure 3: B7-H4 shRNA inhibits cell proliferation by CCK-8 assay 1-4 days. The viabilities of A549-shRNA cells and A549$\mathrm{NC}$ cells were detected at $450 \mathrm{~nm}$. Data was presented as the mean $\pm \mathrm{SD} ; * * * p 0.001$. 


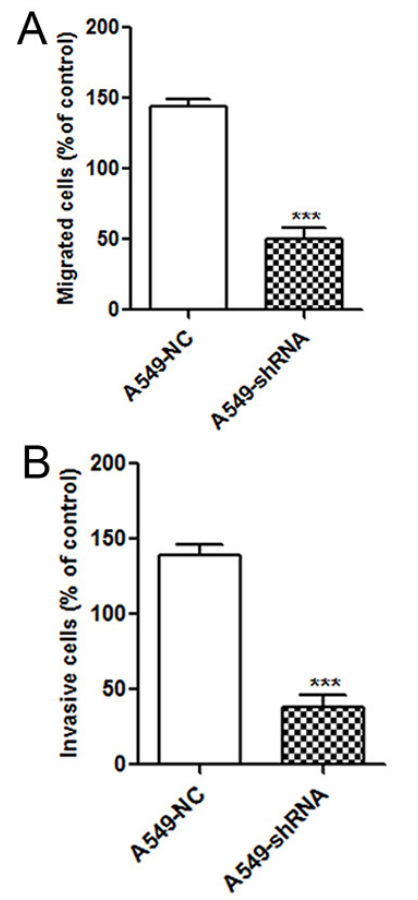

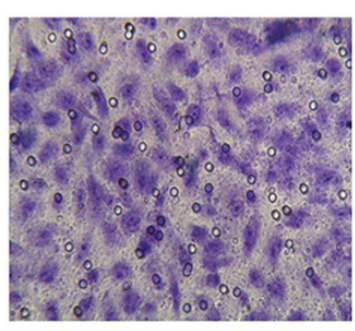

A549-NC

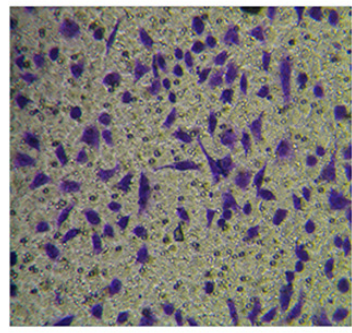

A549-NC

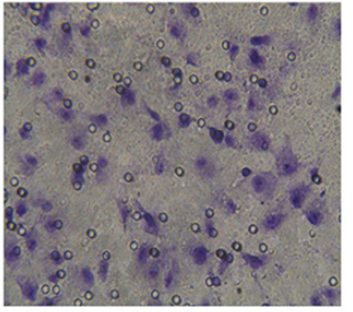

A549-shRNA

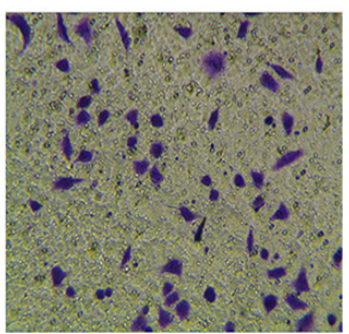

A549-ShRNA

Figure 4: Reducing migration and invasion abilities of A549 cells by lentivirus-mediated RNAi. (A) Effect on tumor migration activity of A549-shRNA cells. A549-shRNA cells and A549-NC cells that migrated through the upper chamber with 8- $\mu \mathrm{m}$ pores membrane were counted and photographed under a light microscope, respectively $(\mathrm{SP} \times 200)$. (B) Effect on tumor invasion activity of A549-shRNA cells. A549-shRNA cells and A549-NC cells that invaded through the Matrigel coated inserts were counted and photographed under a light microscope, respectively $(\mathrm{SP} \times 200)$. Data was presented as the mean $\pm \mathrm{SD} ; * * * p 0.001$.
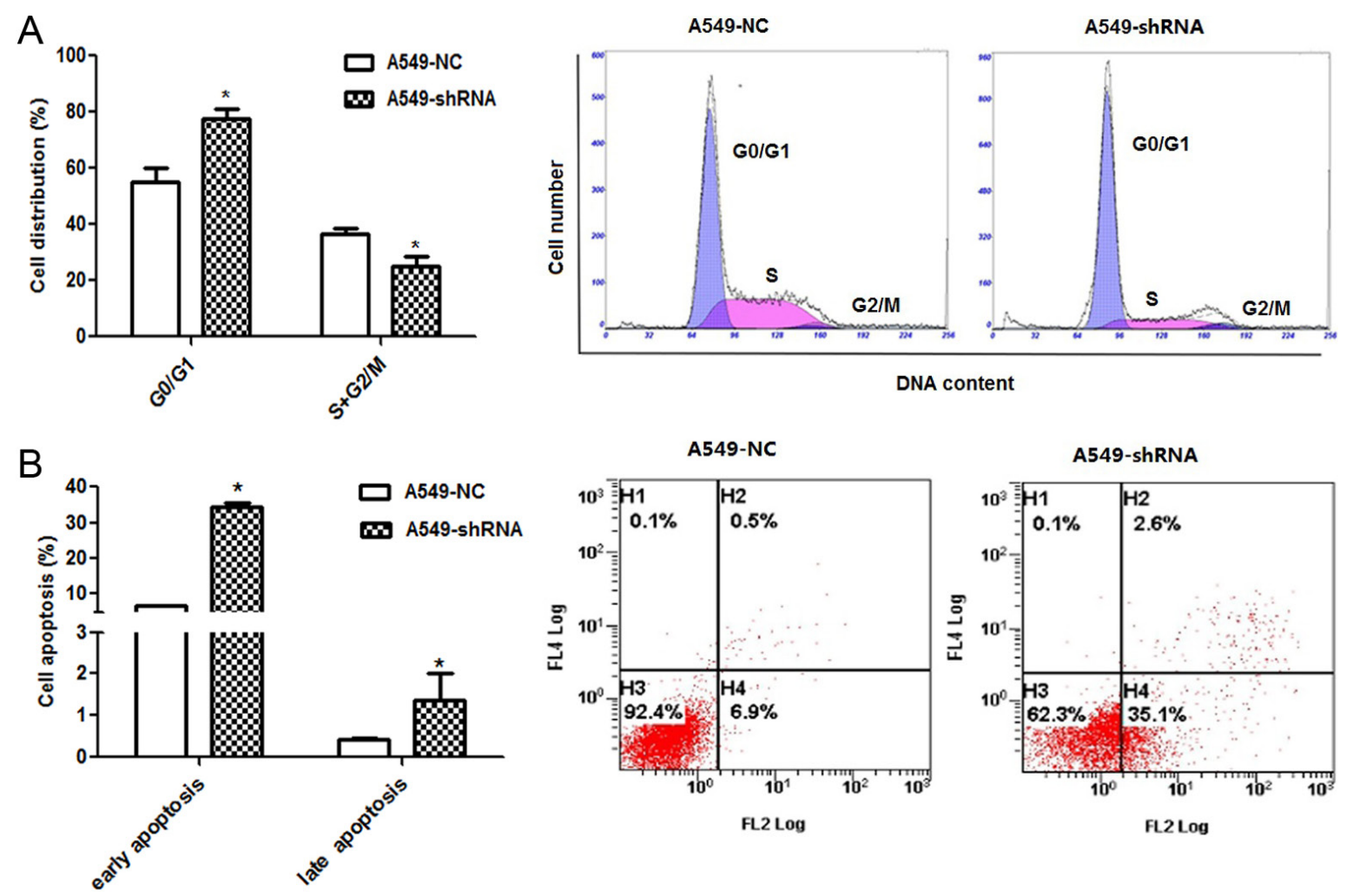

Figure 5: Effect of B7-H4 shRNA on cell circle distribution and apoptosis in A549 cells. (A) Cell cycle distribution was identified by flow cytometry. A549-shRNA cells were arrested in the G0/G1 stage of cell cycle significantly compared with A549-NC cells; (B) Cell apoptosis of A549 cells was detected by by flow cytometry. Data was presented as the mean $\pm \mathrm{SD}$; ${ }^{*} p<0.05$. 

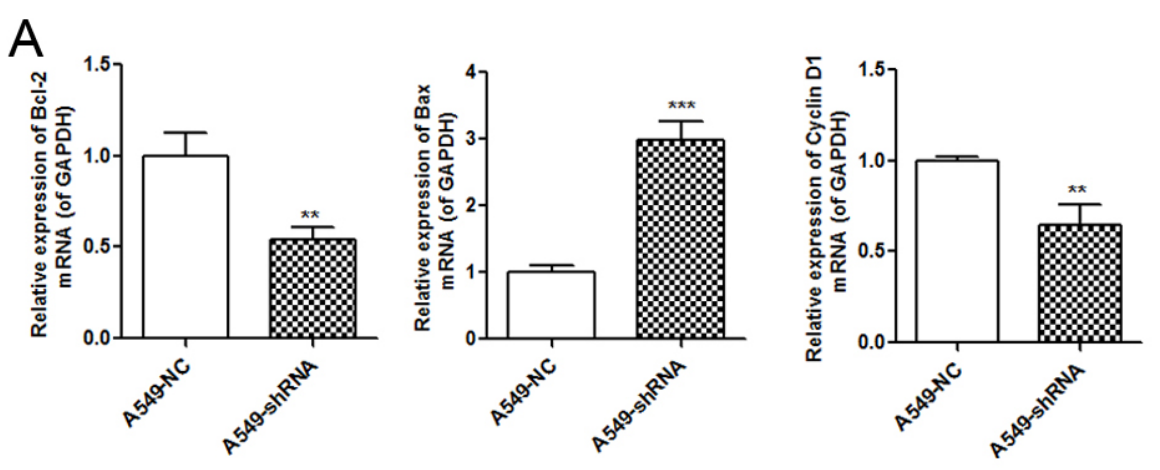

B
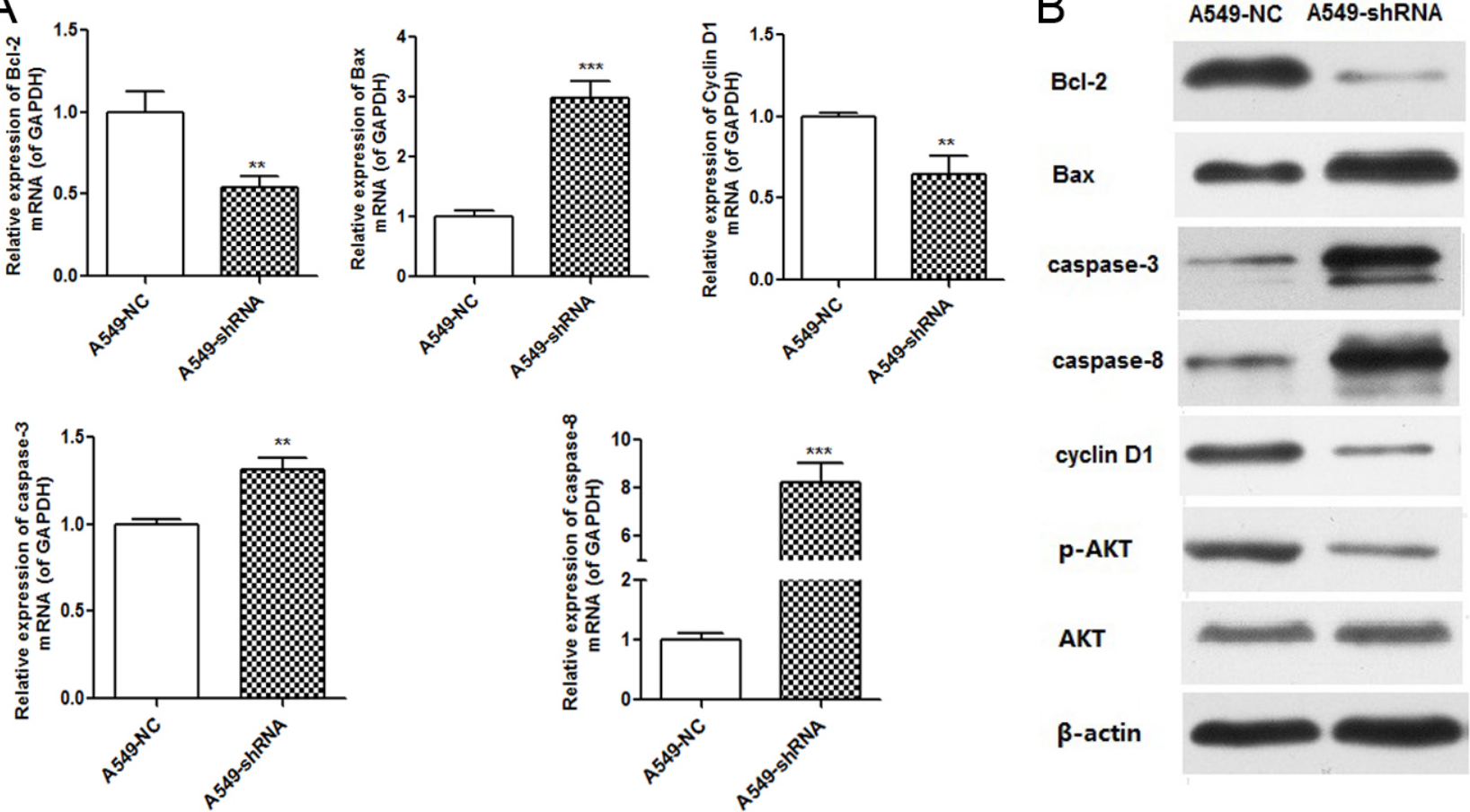

Figure 6: B7-H4 RNAi influenced expression of molecules associated with cell cycle and apoptosis. (A) Quantification of mRNA expression of molecules associated with cell cycle and apoptosis. (B) Protein expression of molecules associated with cell cycle and apoptosis. Data was presented as the mean $\pm \mathrm{SD} ; * * p<0.01, * * * p<0.001$.

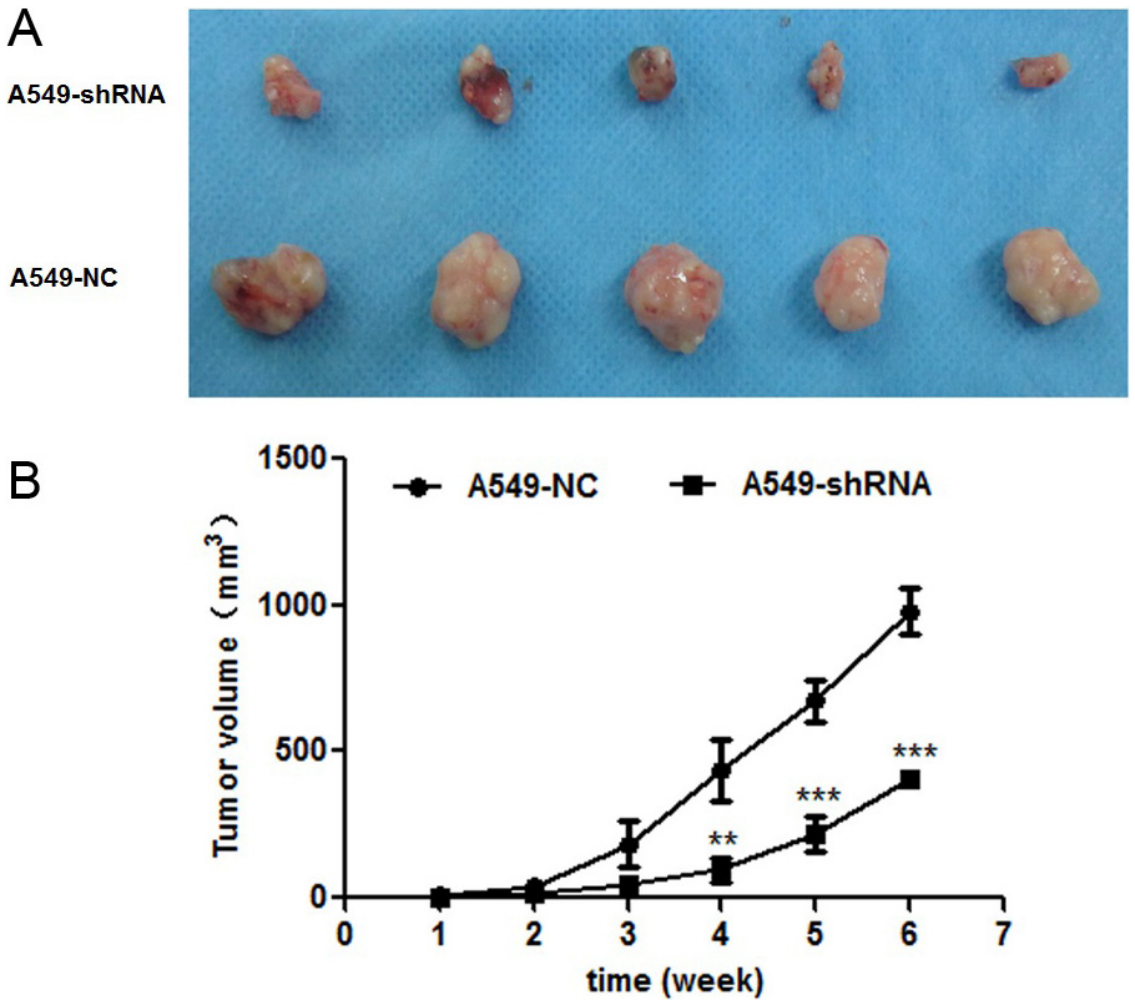

Figure 7: Effect of B7-H4shRNA on lung cancer in vivo. (A) Images of xenografted tumors developed from A549 cells with B7-H4 shRNA and control. (B) Plot of changes in tumor volumes $\left(\mathrm{mm}^{3}\right)$ over time. Size of tumors were measured over a period of 6 weeks with conrol group. Data was presented as the mean $\pm \mathrm{SD} ; * * p<0.01, * * * p<0.001$. 
the effect of B7-H4 on the growth of tumors in vivo. Two groups of xenograft growth provide direct evidences that B7-H4 gene RNAi resulted in the obvious variation in tumor mass. It indicated that B7-H4 gene silencing suppress growth of xenografts in vivo and has a potent therapeutic effect against tumor cells.

The aberrant activation of AKT signaling pathway has a critical influence in many biological processes of human malignancies, including NSCLC [27]. Knockdown of AKT expression suppressed lung cancer cell proliferation [28], and the molecules correlated with apoptosis such as Bcl-2 and caspase-3 are the downstream targets of Akt [29]. In this study, B7-H4 gene silencing induced by B7-H4 shRNA inhibited AKT phosphorylation. AKT phosphorylation inhibition by B7-H4 gene silencing suggested that B7-H4 inhibition could be responsible for decreasing tumor cell oncogenicity, increasing apoptosis, and arresting cell cycle procedure through AKT pathway. It indicates that B7-H4 and AKT signaling pathway might have a bound relationship, Liang Zhang et al. reported that B7-H4 was a cytoplasmic-nuclear shuttling protein, and B7-H4 promoted tumor progression and cell proliferation through translocating into nucleus [30]. But the link between B7-H4 and AKT signaling pathway needs to be furtherly investigated.

In summary, our work from vivo and vitro demonstrated that B7-H4 might be an important cancer promoter and a novel therapeutic target for human lung cancer. B7-H4 inhibition might offer an exciting opportunity to inhibit the progression and metastasis of human lung cancers.

\section{MATERIALS AND METHODS}

\section{Cancer tissues specimens}

Formalin-fixed, paraffin-embedded tumor tissues were obtained from 90 cases of lung carcinomas and 50 cases of adjacent non-tumor specimens (within at least $5 \mathrm{~cm}$ of tumor margin) were also obtained in Affiliated Hospital of Jiangnan University (WuXi No.4 People's Hospital is renamed as the Affiliated Hospital of Jiangnan University), China. The protocol in this study was approved by the ethics committees of the Affiliated Hospital of Jiangnan University.

\section{Immunohistochemical staining}

The paraffin-embedded human lung tumor tissues were cut into $4 \mu \mathrm{m}$-thick serial sections, Immunohistochemical (IHC) staining was performed on human tumor specimens and non-tumor specimens by using Envision methods, these slides were labeled by using primary antibodies specific for B7-H4 (GeneTex, Merck \& Millipore), a negative control was carried out by replacing the primary antibody with PBS, then sections were incubated with horseradish peroxide-labeled goat anti-Rabbit second antibody (Merck \& Millipore). Semiquantitative measurements of staining intensity (0-3, i.e., least intense to most intense) and the proportion of stained cells $(0-4$, i.e., no cells stained to more than $70 \%$ cells stained) were determined as previously described [31]. All slides were examined and evaluated independently by two pathologists.

\section{Cells culture}

A549 cells, derived from human lung adenocarcinoma, were purchased from cell bank of Chinese Academy of Science, Shanghai, in China, and maintained in Roswell Park Memorial Institute (RPMI, Gbico) medium containing 10\% fetal bovine serum (Gbico), 1\% penicillin and streptomyc (Life Technologies) at $37^{\circ} \mathrm{C}$, in a humidified incubator with $5 \% \mathrm{CO} 2$.

\section{Cloning and expression of B7-H4 shRNA}

Four DNA template oligonucleotides corresponding to B7-H4 gene were designed and synthesized. Four pairs of B7-H4 specific shRNA were also synthesized according to four DNA template oligonucleotides sequence. The synthesized single DNA chain was ligated with empty vector GV115 (hU6-MCS-CMV-EGFP, Shanghai genechem Co., Ltd. China). The connected product was transferred to Escherichia coli and cultured on the Amp+LB plate for an over night at $37^{\circ} \mathrm{C}$. The positive colonies were selected and amplified using PCR primers, then inoculated into Amp $+\mathrm{LB}$ liquid medium in shaking bottle at $37^{\circ} \mathrm{C}$ for an over night. The plasmid was extracted by using Axygen plasmid extraction kit (Qiagen, German) and sequenced (invitrogen). Recombinant lentiviral vector was then transfected into 293T cells. Supernatants containing lentiviruses were harvested $48 \mathrm{~h}$ later after transfection. A549 cells were infected with viral supernatants for $12 \mathrm{~h}$ at an appropriate concentration of viral supernatants. After 3 days post-transfection, 90\% of the cells were transfected by observing the expression of GFP. There were respective two experimental groups for A549 cells: cells transfected with lentivirus mediated shRNA-targeted B7-H4 were named A549-shRNA-A, A549-shRNA-B, A549-shRNA-C, A549-shRNA-D cells, cells transfected with lentivirus mediated shRNA (negative control, NC) were named A549-NC cells.

\section{Real-time reverse transcription-PCR}

A549-shRNA cells and A549-NC cells were seeded and harvested after culture 96h. Total RNA was extracted from each group of cells using the Trizol (Invitrogen), cDNA synthesis was obtained using the ThermoScript $\mathrm{t}^{\mathrm{TM}}$ Reverse Transcriptase kit (Life Technologies), then, RTPCR was performed using Power SYBR ${ }^{\circledR}$ Green PCR 
Master Mix (Life Technologies). The mRNA expression of various genes was assessed using ABI 7700 Sequence Detection System (Applied Biosystems). Relative gene expression was quantified.

\section{Cell proliferation assay}

The cell viability of A549-shRNA and A549NC cells were measured by Cell Counting Kit-8Assay (Dojindo, Japan). Two groups of cells, at $1 \times 10^{5} /$ well, were respectively seeded into 96 -well plates, and incubated in the water-saturated carbon dioxide incubator. The absorbance at $450 \mathrm{~nm}$ was measured by using a Model AMR-100 microplate reader.

\section{Cell apoptosis and cycle assays}

Apoptosis assays were performed by using an Annexin V-PE apoptosis detection kit (BD PharMingen). A549-shRNA and A549-NC cells in 6-well plate were digested and collected at 96h, cells were suspended in PBS and stained with Annexin V-PE and 7-ADD (Dojindo, Japan), and detected in a FACS Calibur cytometer (FACS Caliber, BD Biosciences). Annexin V-PE and 7-ADD double-negative cells were considered to be non-apoptotic cells. PI staining kit (Vazyme) was used to detect cycle of cells by using flow cytometry. DNA content of cell was detected according to the relative proportions of cells in the G1/G0, S and G2/M phases of the cell cycle.

\section{Cell migration and invasion assays in vitro}

In migration assay, A549-shRNA and A549-NC cells $\left(1 \times 10^{5}\right.$ cells respectively) suspended with serumfree RPMI medium were seeded to upper chamber with $8 \mu \mathrm{m}$ pores membrane, and $10 \% \mathrm{FBS}$ contained medium were added into lower chamber, then cells were incubated for $12 \mathrm{~h}$ at $37^{\circ} \mathrm{C}$. Cells removed from upper chamber to lower chamber. In invasion assay, A549-shRNA and A549-NC cells $\left(2.0 \times 10^{4}\right.$ cells respectively) suspended with serum-free RPMI medium were seeded to upper chamber, $10 \%$ FBS contained medium were placed in the lower chamber. Then cells were incubated for $24 \mathrm{~h}$ at $37^{\circ} \mathrm{C}$. Cells were removed from upper chamber surface of $8 \mu \mathrm{m}$ pores polycarbonate filter coated with $1 \mathrm{mg} / \mathrm{ml}$ Matrigel (Corning, Inc.) to lower chamber. The cells on the lower surface of the filter were fixed in methanol and stained with $0.1 \%$ crystal violet. The stained cells were washed three times with PBS, and counted in five random highpower fields.

\section{Tumor growth in vivo}

Briefly, A549-shRNA cells and A549-NC cells (both $2.0 \times 10^{7}$ cells) were injected into groin of 8 -week-old male BALB/c nude mice. The size of tumors was observed at intervals of 3 days. The orthotopic xenograft tumors were measured using a caliber and harvested at 42 days after the injection.

\section{Western blot}

A549-shRNA cells and A549-NC cells were lysed in 50ul lysis buffer (Beyotime) on ice for $30 \mathrm{~min}$ respectively. Cells lysates were centrifuged and denatured with SDS polyacrylamide gel electrophoresis (SDSPAGE) sample buffer for $10 \mathrm{~min}$ at $95^{\circ} \mathrm{C}$. Proteins were electrophoresed on $10 \%$ SDS-PAGE gels and transferred to polyvinylidene difluoride (PVDF) membranes. The membranes were blocked with $5 \%$ skim milk in TBST and then incubated with specific antibodies (including B7H4, GeneTex, Merck \& Millipore; Bcl-2/Bax, caspase-3/ caspase-8, p-AKT/AKT, CyclinD1 and GAPDH, Cell Signaling Technology, Inc.) for $2 \mathrm{~h}$ at room temperature. After thorough washes, membranes were incubated with horseradish peroxidase (HRP) conjugated secondary antibody (Santa Cruz, CA).

\section{Statistical analysis}

The association between $\mathrm{B} 7-\mathrm{H} 4$ expression and clinic pathologic features was analyzed by chi-square test. The difference between the groups showed mean \pm standard deviation ( $\bar{x} \pm \mathrm{SD})$, the differences between the groups was analyzed by two-tailed Student's $t$-test. The software of SPSS version17.0 (SPSS, Inc.) was used for statistical analysis. Statistical significance was considered at $p<0.05$ and markedly significance was considered at $p<0.01$.

\section{ACKNOWLEDGMENTS}

We are grateful to Yan Qin and Ruizhen Bai two pathologists of the Affiliated Hospital of Jiangnan University for all slides examination and evaluation in our work.

\section{CONFLICTS OF INTEREST}

The authors declare no conflicts of interest related to the publication of this work.

\section{GRANT SUPPORT}

This work was also supported by Clinical Key Speciality Project of China, Clinical Medical Center of Suzhou (Szzx201502); National Natural Science Foundation of China (31270940 to J-A. Huang); Suzhou Key Laboratory for Respiratory Medicine (No. SZS201617); The Societal and Developmental Project of Suzhou (No. SS201630) and Clinical Key Speciality Project of China. 


\section{REFERENCES}

1. Ferlay J, Soerjomataram I, Dikshit R, Eser S, Mathers C, Rebelo M, Parkin DM, Forman D, Bray F. Cancer incidence and mortality worldwide: sources, methods and major patterns in GLOBOCAN 2012. Int J Cancer. 2015; 136:E359-386.

2. Goldstraw P, Chansky K, Crowley J, Rami-Porta R, Asamura H, Eberhardt WE, Nicholson AG, Groome P, Mitchell A, Bolejack V. The IASLC Lung Cancer Staging Project: Proposals for Revision of the TNM Stage Groupings in the Forthcoming (Eighth) Edition of the TNM Classification for Lung Cancer. J Thorac Oncol. 2016; 11:39-51.

3. Torre LA, Siegel RL, Jemal A. Lung Cancer Statistics. Adv Exp Med Biol. 2016; 893:1-19.

4. Prasad DV, Richards S, Mai XM, Dong C. B7S1, a novel B7 family member that negatively regulates $\mathrm{T}$ cell activation. Immunity. 2003; 18:863-873.

5. Leitner J, Grabmeier-Pfistershammer K, Steinberger P. Receptors and ligands implicated in human $\mathrm{T}$ cell costimulatory processes. Immunol Lett. 2010; 128:89-97.

6. Choi IH, Zhu G, Sica GL, Strome SE, Cheville JC, Lau JS, Zhu Y, Flies DB, Tamada K, Chen L. Genomic organization and expression analysis of B7-H4, an immune inhibitory molecule of the B7 family. J Immunol. 2003; 171:4650-4654.

7. Safaei HR, Rostamzadeh A, Rahmani O, Mohammadi M, Ghaderi O, Yahaghi H, Ahmadi K. Prognostic investigations of B7-H1 and B7-H4 expression levels as independent predictor markers of renal cell carcinoma. Tumour Biol. 2016; 37:7583-7587.

8. Peng HX, Wu WQ, Yang DM, Jing R, Li J, Zhou FL, Jin YF, Wang SY, Chu YM. Role of B7-H4 siRNA in Proliferation, Migration, and Invasion of LOVO Colorectal Carcinoma Cell Line. Biomed Res Int. 2015; 2015:326981.

9. Quandt D, Fiedler E, Boettcher D, Marsch W, Seliger B. B7-h4 expression in human melanoma: its association with patients' survival and antitumor immune response. Clin Cancer Res. 2011; 17:3100-3111.

10. Fauci JM, Straughn JM, Jr., Ferrone S, Buchsbaum DJ. A review of B7-H3 and B7-H4 immune molecules and their role in ovarian cancer. Gynecol Oncol. 2012; 127:420-425.

11. Chen LJ, Sun J, Wu HY, Zhou SM, Tan Y, Tan M, Shan BE, Lu BF, Zhang XG. B7-H4 expression associates with cancer progression and predicts patient's survival in human esophageal squamous cell carcinoma. Cancer Immunol Immunother. 2011; 60:1047-1055.

12. Dong Q, Ma X. B7-H4 expression is associated with tumor progression and prognosis in patients with osteosarcoma. Biomed Res Int. 2015; 2015:156432.

13. Zhu J, Chu BF, Yang YP, Zhang SL, Zhuang M, Lu WJ, Liu YB. B7-H4 expression is associated with cancer progression and predicts patient survival in human thyroid cancer. Asian Pac J Cancer Prev. 2013; 14:3011-3015.
14. Liang L, Jiang Y, Chen JS, Niu N, Piao J, Ning J, Zu Y, Zhang J, Liu J. B7-H4 expression in ovarian serous carcinoma: a study of 306 cases. Hum Pathol. 2016; 57:1-6.

15. Qian Y, Sang Y, Wang FX, Hong B, Wang Q, Zhou X, Weng $\mathrm{T}$, Wu Z, Zheng M, Zhang H, Yao H. Prognostic significance of B7-H4 expression in matched primary pancreatic cancer and liver metastases. Oncotarget. 2016; 7:72242-72249. doi: 10.18632/oncotarget.12665.

16. Chen L, Xie Q, Wang Z, Shi L, Wu C, Jiang J. Assessment of combined expression of B7-H3 and B7-H4 as prognostic marker in esophageal cancer patients. Oncotarget. 2016; 7:77237-77243. doi: 10.18632/oncotarget.12628.

17. Salceda S, Tang T, Kmet M, Munteanu A, Ghosh M, Macina R, Liu W, Pilkington G, Papkoff J. The immunomodulatory protein B7-H4 is overexpressed in breast and ovarian cancers and promotes epithelial cell transformation. Exp Cell Res. 2005; 306:128-141.

18. Qian Y, Hong B, Shen L, Wu Z, Yao H, Zhang L. B7-H4 enhances oncogenicity and inhibits apoptosis in pancreatic cancer cells. Cell Tissue Res. 2013; 353:139-151.

19. Shangary S, Oliver CL, Johnson DE. The Intrinsic (Mitochondrial) Death Pathway and New Cancer Therapeutics: Bcl-2 Family in Focus. In: Los M and Gibson SB, eds. Apoptotic Pathways as Targets for Novel Therapies in Cancer and Other Diseases. (Boston, MA: Springer US), pp. 107-135.

20. Antonsson B. Bax and other pro-apoptotic Bcl-2 family "killer-proteins" and their victim the mitochondrion. Cell Tissue Res. 2001; 306:347-361.

21. Tait SW, Green DR. Mitochondria and cell death: outer membrane permeabilization and beyond. Nat Rev Mol Cell Biol. 2010; 11:621-632.

22. Wang $X$. The expanding role of mitochondria in apoptosis. Genes Dev. 2001; 15:2922-2933.

23. Liu Q, Chi X, Leber B, Andrews DW. Bcl-2 Family and Their Therapeutic Potential. In: Wu H, ed. Cell Death: Mechanism and Disease. (New York, NY: Springer New York), pp. 61-96.

24. Reed JC. Dysregulation of Programmed Cell Death in Cancer toward a Molecular Understanding of Bcl-2. In: Mihich E, Croce C, eds. The Biology of Tumors. (Boston, MA: Springer US), pp. 145-171.

25. Santo L, Siu KT, Raje N. Targeting Cyclin-Dependent Kinases and Cell Cycle Progression in Human Cancers. Semin Oncol. 2015; 42:788-800.

26. Meikrantz W, Schlegel R. Apoptosis and the cell cycle. Journal of Cellular Biochemistry. 1995; 58:160-174.

27. Shi Y, Chen L, Li J, Lv YL, Sun Q, Wang LX, Jiao SC. Prognostic and predictive values of pERK1/2 and pAkt-1 expression in non-small cell lung cancer patients treated with adjuvant chemotherapy. Tumour Biol. 2011; 32:381-390.

28. Yuan Y, Du W, Wang Y, Xu C, Wang J, Zhang Y, Wang H, Ju J, Zhao L, Wang Z, Lu Y, Cai B, Pan Z. Suppression of 
AKT expression by miR-153 produced anti-tumor activity in lung cancer. Int J Cancer. 2015; 136:1333-1340.

29. Shi M, Zhang H, Li M, Xue J, Fu Y, Yan L, Zhao X. Normal endometrial stromal cells regulate survival and apoptosis signaling through PI3K/AKt/Survivin pathway in endometrial adenocarcinoma cells in vitro. Gynecol Oncol. 2011; 123:387-392.

30. Zhang L, Wu H, Lu D, Li G, Sun C, Song H, Li J, Zhai T, Huang L, Hou C, Wang W, Zhou B, Chen S, Lu B, Zhang X.
The costimulatory molecule $\mathrm{B} 7-\mathrm{H} 4$ promote tumor progression and cell proliferation through translocating into nucleus. Oncogene. 2013; 32:5347-5358.

31. Zhang $\mathrm{X}$, Zhang G, Qin Y, Bai R, Huang J. B7-H6 expression in non-small cell lung cancers. Int J Clin Exp Pathol. 2014; 7:6936-6942. 